\title{
LDL Particle Size Measurement
}

National Cancer Institute

\section{Source}

National Cancer Institute. LDL Particle Size Measurement. NCI Thesaurus. Code

C103412.

The determination of the amount of the average particle size of low-density lipoprotein in a sample. 